\title{
Moral responsibility in psychopathy: a clinicophilosophical case discussion
}

\author{
Steve Ramplin \& Gloria Ayob
}

\begin{abstract}
SUMMARY
This article examines the concept of moral responsibility in psychopathy. In doing so it shows how philosophical ideas can be used to help approach a complex issue in psychiatry. Building on a fictitious case, we explore two arguments: the exempting view, which proposes that psychopaths lack any ability to function as moral agents; and the mitigating view, which concedes that there are impairments in moral understanding in psychopathy, but takes these to be insufficient to be completely exempting, instead concluding that such individuals are at least partially morally responsible. Typically, clinicians (and the courts) are more comfortable with a mitigating view, whereas philosophers tend to extol an exempting view. Through discussion of the case, we illustrate the value that philosophy brings to clinical psychiatry and the ways in which psychiatry can enrich philosophical debate.
\end{abstract}

\section{LEARNING OBJECTIVES}

- Appreciate the diversity of views about moral responsibility in psychopathy, ranging from mitigation to exemption

- Understand the philosophical arguments used to support both the mitigating and exempting views

- Consider the benefits of philosophical reasoning in explicating a complex problem in psychiatry

\section{DECLARATION OF INTEREST}

None

Psychiatry is replete with the kind of conceptual complexity that is ideal for deeper philosophical reflection. ${ }^{a}$ One particularly thorny problem is how moral responsibility (a topic richly debated in philosophy: Box 2) is influenced by various mental disorders. It is probably relatively uncontroversial that a person's moral responsibility for an action can be reduced, or occasionally even negated, by mental illnesses characterised by impaired rational judgement, of which acute psychosis is the example par excellence. However, because voluntary control of an action is a key aspect of moral responsibility, loss of control can also undermine it, which inevitably brings other mental disorders into consideration.

One example is personality disorders, although these are not as readily accepted as a valid excuse: that is to say, people, including mental health professionals, are less willing to forgive challenging behaviour in such individuals. The reasons for this are complex, but generally reflect the view that individuals with personality pathology are more able to understand and, at least to some minimum extent, control their actions.

\section{Psychopathy and moral responsibility}

The clinical construct of psychopathy (Box 3) exemplifies this problem. As a concept, psychopathy is defined by the Psychopathy Checklist (revised) (PCL-R) (Hare 1991). This 20-item construct rating scale uses a semi-structured interview, case history information and specific criteria for each perceived personality trait or recorded behaviour to provide a reliable and valid estimate of the degree to which an individual matches the prototypical idea of the psychopath. Those so classed are typically superficially charming but manipulative and remorseless; they lack empathy, will take advantage of others and are irresponsible and impulsive. Frequently, such individuals may also show early-onset poor behavioural control, criminal versatility and recidivist offending. It is perhaps evident that psychopathy has much in common with the overlapping concept of dissocial (or antisocial) personality disorder, although they are in fact distinct.

In the philosophical literature on psychopathy, it is not uncommon to encounter the claim that psychopaths should be exempted from moral responsibility because they are blind to moral reasons. In just the way that colour-blind individuals do not possess the resources required to participate in colour-based language games, so psychopathic individuals do not possess the resources required to participate in our moral practices (Duff 1977, 2010). Yet, there is a general
Steve Ramplin is a consultant forensic psychiatrist at the Priory Hospital, Middleton St George. He has an academic interest in the philosophy of psychiatry and co-edits the newsletter of the Philosophy Special Interest Group of the Royal College of Psychiatrists. Gloria Ayob lectures on the MA Philosophy and Mental Health programme at the University of Central Lancashire. Her research interests in the philosophy of psychopathology include the nature of disordered states, autonomous agency and self-understanding. Correspondence Dr Steve Ramplin, The Priory Hospital, Middleton St George, Darlington DL2 1TS, UK. Email: SteveRamplin@ priorygroup.com

Copyright and usage (C) The Royal College of Psychiatrists 2017

a. Box 1 has a glossary of terms used in this article. 


\section{BOX 1 Glossary}

Attributionism: the position that a person can be responsible for an action if it reflects their usual character

Control condition: with reference to voluntariness, the requirement that a person exercises control over their movements in performing an action

Conventional transgressions: actions out of keeping with what would be expected given the social context (such as eccentric behaviour or etiquette violations), normally contrasted with moral transgressions

Diminished responsibility: in English law, a legal defence against a charge of murder, arising from an abnormality of mental functioning, which permits sentencing discretion when successfully pleaded

Egocentric thinker: one who solely considers his or her own perspective

Epistemic condition: with reference to voluntariness, the requirement that a person is aware an action is their own and performed as per their intention

Exempting view: the position that a psychopath's blindness to moral reasons morally responsible for his actions is such that he cannot justifiably be held
Mitigating view: the position that a psychopath's factual understanding of a morally bad action is sufficient for him to have some moral responsibility for his action

Moral responsibility: the extent to which an individual deserves to receive reward (such as praise) or punishment (such as condemnation) for an act or omission

Moral transgressions: these are generally understood to be universal and, in contrast to conventional transgressions, pertain to the proscription of harm and the prescription of promoting the welfare of others

Normative: related to a standard or norm, especially of behaviour

Not guilty by reason of insanity: a legal defence that exculpates a defendant of all responsibility for their crime

Psychopathy: a behavioural construct that is now defined by a high score on the PCL-R (psychopathy checklist, revised); psychopaths are typically callous, manipulative and remorseless

Reactive attitudes: a range of natural responses to an action performed by another, which are influenced by how their motive is perceived reluctance to completely withhold the ascription of moral responsibility from psychopathic individuals. Such reluctance is inevitably played out in adversarial legal arenas when defendants labelled as psychopaths come to trial. This tension is most pointedly demonstrated in English law in cases of murder, when the only defence likely to succeed in respect of such individuals is that of diminished responsibility, rather than the exculpatory defence of not guilty by reason of insanity.

In contrast with the exempting view (which asserts that the psychopathic individual is not a moral agent), a verdict of manslaughter on the grounds of diminished responsibility implies that psychopathic individuals are partial moral agents, albeit ones whose moral agency is significantly impaired. We explore this divergence of views about the moral status of the psychopath in what follows. For brevity, we shall call the contrasting views about moral responsibility in psychopathy the exempting view and the mitigating view. We aim to explore both perspectives by way of a philosophical conversation. However, before sketching out either view we will present an illustrative, though fictitious, case vignette.

\section{Case vignette: John}

John, 23, is the second son of two teachers. Neither his parents nor his siblings have had any problems with offending or with their mental health. John first presented with delinquency at an early age and by age 7 was enrolled in a school for children with emotional and behavioural difficulties. Despite being assessed as having above average intelligence, he did not respond to the increased supervision. He had few friends and often caused arguments between his peers by spreading false rumours about them. He frequently broke school rules and was also arrested by police for vandalism and theft on several occasions while truanting. By his early teens, he was regularly bingeing on illicit drugs and alcohol. He fought with peers and

BOX 2 A brief overview of the philosophy of moral responsibility

Moral responsibility refers to the extent to which an individual deserves to receive a reward, such as praise, or a punishment, such as blame, for an act or an omission. Such judgements are normative and reflect the societal context.

The earliest account of moral responsibility is found in Aristotle's Nicomachean Ethics (Brown 2009). Aristotle argued that people should only be held responsible - that is, praised or blamed - for actions within their voluntary control. The two conditions generally accepted as necessary for voluntariness are: (a) that the agent is aware of the action he is performing (the epistemic condition); and (b) that the agent exercises control over his movements and environment in performing the action (the control condition). By contrast, Aristotle argued that people should not be held responsible for involuntary acts, meaning those driven by a compulsion (such as an external cause) or undertaken in ignorance.

One alternative position to arguments about moral responsibility based on awareness and control are attributionist theories, which contend that an agent can be responsible for an action if it reflects their 'deep self'. Broadly, this means their value perspective (the degree to which a person generally judges an action to be good or bad - for instance, while most people think lying is bad, a minority condone it). Therefore, agents can be morally responsible even if they lack moral understanding, although this position has of course been challenged - by Levy (2007), for instance.

Another theory is that of P. F. Strawson (2003), who argued that moral responsibility can be understood in terms of 'reactive attitudes', essentially a wide variety of natural responses to the way another person's will is perceived. Examples include resentment or anger, gratitude or joy. Such attitudes guide our responses to another person's perceived will: for example, you might feel annoyed with someone who bumps into you causing you to spill your drink. Sometimes, however, reactive attitudes can be adjusted. For example, your annoyance over the spilled drink might be set aside if it is discovered to be in response to an accident, such that the agent did not intend ill will and is therefore not responsible. At other times - for example, in respect of an agent who is mentally ill - a more objective perspective can replace the reactive response. 
threatened to harm his mother several times. At age 13 , he burned down his father's shed, destroying his collection of trophies. A year later, his brother's dog went missing after John removed its collar and let it out following an argument with him.

John left school at age 16 with no qualifications and joined the army. He was warned several times for insubordination, before he was compulsorily discharged without completing his basic training after he set fire to a storehouse. After a period in military custody, he lived with a succession of girlfriends, although he was often unfaithful and financially exploitative. Intermittently, he worked in a variety of unskilled jobs, but he typically ceased to attend, seemingly on a whim, and otherwise was often sacked for theft, poor attendance or perceived bad attitude - on one occasion he was convicted for embezzlement of a former employer.

John continued to offend, receiving several convictions for assault and affray. After failing to pay fines or observe the conditions of community disposals, he served a number of short prison sentences.

Twice, John was also briefly admitted to psychiatric hospital. Both times, he was brought in by police concerned for his well-being after his arrest for some minor misdemeanour. One time, he claimed to have suffered a head injury while on active service in the army that he said caused him to hear voices. He also claimed to have been a semiprofessional boxer. On each occasion, there was no evidence of psychosis and any claimed symptoms resolved shortly after admission. On the ward, he was usually disruptive. For example, he smuggled in alcohol, provoked fights between other patients and on one occasion persuaded a peer who was very unwell to escape with him. He was diagnosed with antisocial personality disorder.

\section{Introducing the mitigating view of moral responsibility in psychopathy}

The mitigating view holds that psychopaths like John retain at least partial moral responsibility for their actions. A key driver for this view is the veneer of normalcy shown by such individuals indeed, it is for this reason that Cleckley's original thesis on psychopathy was titled The Mask of Sanity (Cleckley 1988). This apparent normalcy surely contributes to psychopathic defendants receiving verdicts that imply partial moral responsibility instead of being exempted from responsibility, in the adversarial arena of a contested diminished responsibility case. Finally, despite evidence that psychopaths do not have complete moral understanding of their actions, they appear to retain a factual, or cognitive, understanding of them. This kernel of knowledge underpins the mitigating view.

When thinking about the nature of a particular type of mental disorder, philosophers often contrast it with cases it is interestingly different from, with the aim of sharpening the characterisation of the disorder under consideration. In psychopathy, the

BOX 3 Psychopathy and its relationship to dissocial personality disorder

The notion of psychopathy as it is now understood was introduced by Hervey Cleckley in his book The Mask of Sanity (1988). Originally published in 1941, it uses numerous case studies to draw out a description of psychopathy. In the (posthumous) 1988 edition, Cleckley asserted that psychopaths have 'a genuine and very serious disability, disorder, defect or deviation' (p. 367), and claimed that their central deficit was a persistent failure of empathy. He identified 16 key characteristics, which were later subsumed into the current main tool used to establish the presence of psychopathy, Hare's Psychopathy Checklist - Revised, abbreviated to PCL-R (Hare 1991).

The PCL-R is a 20-item clinical rating scale, with each item scored as absent, partial or definite according to how information derived from an extensive file review and a semi-structured interview compare to the following criteria, which fall largely into two categories
Factor 1 (interpersonal/affective):

- glib/superficial charm

- grandiose sense of self-worth

- pathological lying

- cunning and manipulative

- lack of remorse or guilt

- shallow affect

- callous/lack of empathy

- failure to accept responsibility for one's actions

Factor 2 (impulsive/antisocial):

- parasitic lifestyle

- poor behavioural controls

- early behavioural problems

- lack of realistic long-term goals

- impulsivity

- irresponsibility

- juvenile delinquency

- need for stimulation/proneness to boredom

- revocation of conditional release. contrast classes often discussed when considering moral status have tended to be delusion and addiction. Delusional individuals offer an interesting comparison because those who are deluded are typically more readily exempted from responsibility. Conversely, despite frequently lacking control, those who are addicted are less readily exempted from responsibility. These conditions also correspond to each of the two conditions generally accepted as necessary for voluntary agency, which have already been outlined in Box 2 (the epistemic and control conditions). By contrast with delusional and addicted agents, psychopathic agents like John seem to meet both of these conditions, so intuition tells us they ought to be responsible for their actions.

Before considering the mitigating view as applied to John, let us emphasise those aspects of his case that suggest he is a psychopath. Clearly, his behaviour meets many of the criteria of the PCL-R. His lack of tenacity suggests a proneness to boredom. He is dishonest with girlfriends, peers, police and professionals, sometimes for apparently calculated reasons. Many of his actions appear callous. He is parasitic, for example, by exploiting partners for his own benefit. He is impulsive, irresponsible and does not cooperate with conditional punishments. He manipulates for his own advantage, for example, by seeking 
hospital admission to escape justice. In short, he seems like a prototypical psychopath.

\section{The mitigating view and the case of John}

Let us consider the epistemic condition first. Psychopathic agents like John appear to know what they are doing, as least under factual (non-moral) specifications of action. That is, his factual description of his action matches ours. For example, John's release of his brother's dog seems quite deliberate, especially given that it was preceded by the act of removing the identifying collar. Similarly, his act of cultivating recurrent short-term relationships seems calculated to provide a source of money and somewhere to live, as well as sexual contact. Over and above evidence of factual understanding, despite claims of 'voice-hearing', there is no evidence of psychotic irrationality. This characterisation contrasts with a delusional agent, who usually has a radically different understanding to those around him about what it is he is doing when he acts intentionally (or tries to).

Let us now consider the control condition: actions performed by a psychopathic agent do not appear to be driven by overriding impulses or urges of the type demonstrated by an addicted agent. Consider John again: despite his history of bingeing on alcohol and illicit drugs, his behaviour does not seem compulsive in the way that an addict's behaviour does.

So if the psychopathic agent (illustrated by our vignette) satisfies the conditions of voluntary agency, and if voluntary agency is sufficient for the status of a moral agent, it suggests that the psychopathic agent is indeed a moral individual.

\section{Introducing the exempting view of moral responsibility in psychopathy}

The exemption theorist would argue that, although John knows enough about his own situation factually to exploit his partners, he is unable to grasp that such deceit is morally wrong. As such, he sees no point whatsoever in exercising control to desist from this action. Similar claims could also be made about his other immoral acts. Underpinning this response is the idea that our actions can be specified in more than one way: they can be specified using factual or descriptive concepts, and they can be specified using normative or moral concepts. For the purpose of establishing moral agency, the exemption theorist contends that it is the latter kind of specification that is germane to determining whether or not the agent satisfies the epistemic and control conditions.
Thus, the epistemic (awareness) and control conditions of voluntary agency, as envisaged by the mitigating theorist, are too indeterminate to be of much use in settling the question about whether psychopaths can rightly be held morally responsible for their actions.

According to the exemption theorist, then, the critical question is this: can the psychopath really be said to know what he is doing, not just factually, but also normatively, meaning based on what is considered to be the normal or correct way of doing something? According to this line of response, in order to ascribe moral responsibility, the epistemic condition of voluntary agency must be specified not just factually, but also normatively, that is in terms of moral concepts. Similarly, for exemption theorists, defining the control condition purely factually is also insufficient: such theorists argue that exercising control requires not merely that the agent be free from compulsion, but also that the exercise of control, in the manner that is prescribed by norms (including moral norms) is intelligible to the agent. In other words, the controlling perspective does not come from nowhere. It must be anchored in an agent's understanding of the point of exercising control, and much of the point of exercising control derives from our understanding of the various norms that constrain human life.

This point is usually put in terms of reasonsresponsiveness: exemption theorists assert that the psychopath is blind to moral reasons, meaning that he is not reasons-responsive in the domain of moral reasoning (Duff 2010). In turn, this means that the psychopath does not inhabit a perspective from which the exercise of control, in the manner prescribed by moral norms, means very much at all.

It has been widely observed, at least since Cleckley's seminal work, that psychopathic individuals are less capable than the general population of controlling their impulses for the sake of achieving longer-term goals. More broadly, they fail to pursue a coherent life plan. This feature has been taken to signify the presence of serious impairments in the psychopathic individual's capacity for exercising control, not just within the moral sphere but in life generally (see Litton (2008) for a recent exploration of this point). This raises interesting questions about the nature of impulsivity in psychopathy, but it is worth distinguishing two interrelated but distinct questions here: does the psychopath see the point of exercising control at all, in the light of moral, social, and prudential norms; and if he does see the point of doing so, does he nonetheless find it more 
difficult than a healthy (non-psychopathic) agent to exercise control? In claiming that the psychopath is blind to reasons - moral, conventional, prudential - the exemption theorist is addressing the first question. He contends that the psychopath fails to meet the control condition by virtue of failing to grasp any of the normative considerations that would render the exercise of control intelligible.

\section{Revisiting the mitigating view}

One of the joys of studying philosophy is that it helps develop the skill of formulating an argument. In this spirit, let us explore some responses from the mitigating view to the counter-argument proposed by the exemption theorists.

The mitigating theorist would argue that the psychopath does know and can control what he is doing, not just factually but also normatively, at least to a minimally necessary degree. There is some evidence that might support this assertion.

When Glover (2014: p. 36) interviewed patients with psychopathy in a high secure hospital, he found evidence of a "morality emphasising fairness and rights, but [...] with its roots not in empathy for others'. Typically, his interviewees cited a rule-based, authority-derived command morality (p. 28). He gives several examples, including not swearing because of a parental prohibition; patriotic obedience; and the expectation of fairness or equal treatment. The acknowledgement of some sort of moral understanding, albeit incomplete, appears to support the mitigating view.

Arguably, our case vignette contains examples of at least partial moral understanding. For instance, implicit in John's release of his brother's pet dog is the knowledge that the absence of an identifying collar makes it more likely that the pet will not be found, otherwise why take the additional step of removing it? Given the retaliation motive suggested by the action following an argument, it additionally implies that John knows on a factual level that a higher likelihood of permanent loss will be more distressing to his brother. While this does not mean he understands that it is arguably more morally bad, it does provide evidence that psychopaths such as John can appreciate that some moral transgressions are worse than others.

\section{The moral-conventional distinction}

Quite probably, the exemption theorist would at this point cite the moral-conventional distinction. Moral transgressions are defined by the consequences such actions have for others. For example, assaulting someone is a moral wrong. By contrast, conventional transgressions are defined by the consequences such actions have for the social order - for example, wearing pyjamas instead of your usual clothes to go shopping. Owing to the harm they can cause to victims, actions associated with a moral contravention are generally seen as more serious, and also as not permissible even if not explicitly prohibited by a rule.

On the surface, John's case illustrates both types of transgression. For example, the easily imagined greater emotional pain suffered by John's brother when he discovers his missing pet's collar and deduces the deliberately caused low probability of recovery is arguably associated with a moral harm. By contrast, John's habit of breaking rules at school, his insubordination in the army, his recurrent on-a-whim abandonment of employment and his tendency not to pay fines or adhere to the conditions of community sentences are all examples of conventional transgressions.

Evidence suggests that psychopaths see moral transgressions no differently to conventional (rule-based) transgressions; that is, they fail to grasp the moral-conventional distinction. Blair (2005: pp. 57-58) has shown that psychopaths have considerable difficulty with the moralconventional distinction task. Furthermore, although psychopaths do generally regard moral transgressions as more serious than conventional ones, they are far less likely to make reference to victims when explaining why this is so. They are also far less likely to distinguish between the two types of transgression when any rules prohibiting them are removed (Blair 2005: pp. 57-58). Glover's (2014) data supports this view. Levy (2010: p. 222) has also cited this notion in favour of an exempting view, by arguing that psychopaths cannot be responsible because they are 'insensitive to the fact that paradigm moral transgressions necessarily cause distress in victims, regardless of the system of rules in place [...] [in essence] they do not "get" the moral/ conventional distinction'.

\section{Reactive attitudes}

One possible response to this position available to the mitigating view comes from Strawson's theory of reactive attitudes (Box 2). The behaviour of a psychopath typically appears sufficiently rational to be attributed to his will, as perceived by the recipient of or witness to the behaviour. Consequently, a psychopath such as John is a likely recipient of reactive attitudes. When a psychopath's behaviour causes harm, the reactive attitudes will be negative - for example, resentment or anger. Even if such reactive attitudes are modified on learning that the agent had moral deficits 
associated with psychopathy, given the apparent normalcy of such individuals, any modification is likely to be partial, perhaps at best a reappraisal towards mere condemnation. As such, by acting the way that they do, psychopaths like John are inherently blameworthy.

However, a further related point can be made. It seems inherently plausible that even if the psychopath is unable to perceive moral rules, which would otherwise guide him against acting in a certain way, his experience as a recipient of negative reactive attitudes in response to his own harmful actions must contribute to the development of his system of conventional rules, from which his apparent rule-based command morality is potentially derived.

For example, one can imagine the opprobrium directed at John when the immolation of his father's trophies was discovered, a response presumably rooted in the moral understanding of his parents or others. Even if this was adopted by John as a specific conventional rule (one could frame it thus: it is right to show respect to one's parents), such a rule would be influenced in its development by the moral indignation expressed in response to his act. This lends support to the mitigating view, because the psychopath's rule-based morality is derived from his experience as the recipient of reactive attitudes expressed by those capable of moral understanding. That is to say, it is only by being included in the moral community that psychopaths can ever hope to develop morally and thus eventually become moral agents.

\section{Some responses from the exempting view}

However, the exemption theorist claims that even if the psychopath is capable of understanding conventional rules, he possesses no moral understanding. Let us now examine three arguments made in defence of this claim.

\section{The gap between intellectual understanding and moral reasoning}

The first point is that moral reasoning is not simply a type of intellectual reasoning, such that anyone capable of intellectual reasoning (including the psychopath) would thereby be capable of engaging in moral reasoning. As suggested by the moralconventional distinction, there is arguably a clear gap between intellectual reasoning and moral reasoning - and it is one that can only be filled by affective capacities, notably those that relate to empathy.

Psychopaths like John are egocentric thinkers who regard others as instruments of their will, rather than as agents who may judge their own goals to be good. That is, unlike a fair-minded agent, an egocentric agent fails to grasp that other people are separate, autonomous agents too. The case vignette we have been discussing offers several such examples: John exploits his partners for accommodation, money and sex; he shows no qualms about leaving employers in the lurch if it suits him; and he seems to enjoy creating dissent between others.

If moral reasoning were simply a species of intellectual reasoning, then the general axioms of practical reasoning should apply straightforwardly in the moral domain. In particular, it should be possible to demonstrate to an egocentric thinker the fact that he is irrational because he commits an inconsistency in reasoning in an exclusively selfinterested manner. It follows that the egocentric thinker would inevitably then be compelled by the demand of consistency to reject egocentric reasoning. It has been pointed out by Deigh (1995), however, that it is not possible to demonstrate to an egocentric thinker that he is irrational, on the grounds of inconsistency, if the egocentric thinker does not see his own circumstances as relevantly similar to the circumstances of others to begin with. Thus, for instance, he could (without inconsistency) think that others ought not to interfere with his freedom and well-being and at the same time think that he may interfere with theirs (Deigh 1995: p. 756). Such is the case with John, who seemingly treats others with complete disregard, while simultaneously expecting fair treatment (such as sympathetic diversion to hospital if he seems to be mentally unwell). This shows that moral reasoning ultimately rests on the way we regard others in relation to ourselves - and that requires empathy.

In sum, if right regard of others is the foundation on which the capacity for moral reasoning rests, and if empathy is necessary for being able to regard other people aright (viewing them not as instruments of our will but as agents with their own interests and goals), then intellectual understanding alone cannot underwrite the principles that are essential for moral reasoning. Lacking the capacity for empathy and the ability to see others aright, the egocentric thinker (the psychopath) cannot bridge the gap between intellectual reasoning and moral reasoning.

That this gap exists is an important reason for holding that the psychopath grasps only conventional rules. Understanding these alone does not equip him with the kind of understanding that is required for being a moral agent, and it is for this reason that psychopaths like John ought to be exempted from moral responsibility. 


\section{Developmental immaturity}

Empathy, conceived in the terms just described, is a complex capacity. It emerges from early experiences of shared feeling, and evolves through a process of maturation into increasingly sophisticated forms, as our understanding of what it is to be an autonomous human agent deepens (Deigh 1995: p. 759). Developmental immaturity is widely recognised in children as a reason for withholding the ascription of moral understanding - and thus of moral agency (we are not inclined to view very young children as moral agents at all).

Typically, the depth of moral understanding manifested by human adults varies, often quite significantly. Most importantly, the development of the capacity for moral understanding involves participating in what is an inherently normative practice, and coming to grasp the content of moral norms and their relevance to our actions is a creative, multi-faceted endeavour (engaging a range of cognitive, affective and volitional capacities). In view of the rich and complex nature of moral understanding, it is at least logically possible for a biological adult to show underdeveloped moral understanding - and there are grounds for thinking that the absence of moral understanding is more than a mere logical possibility. Hence, the challenge from the exemption theorist is to place the onus on the mitigating theorist to show that there are grounds for ascribing to a particular individual the status of moral agent, despite the appearance of developmental immaturity.

In John's case, his lack of moral awareness is in some respects surprising, as neither his parents nor his brother exhibit similar problems. Indeed, as the son of two teachers, one imagines he would have had the advantage of a secure upbringing that under normal circumstances would be associated with unproblematic moral development. That this has not occurred suggests an inherent deficit, and that John remains immature in his moral development.

In such cases, Deigh's (1995) view that the psychopath's true predicament is a form of immaturity rather than one of irrationality seems sound. To be clear, although in general it is true that rationality is an achievement of maturity, the point of treating the two notions as mutually exclusive in this particular context is to emphasise the fact that the psychopath does not meet the preconditions for moral reasoning - and so, strictly speaking, is neither rational nor irrational. The claim that the psychopath is irrational is ambiguous, in that it could be taken to imply that he satisfies these conditions but wilfully disregards, say, the appeal to consistency. It is precisely this latter claim that Deigh's argument aims at dislodging, hence the formulation of the point here in terms of the notion of immaturity, rather than that of irrationality.

\section{Conditions hazardous to the development of empathy}

The philosopher Susan Wolf (1980) has also drawn attention to the fragility of empathic maturation and moral development.

Let us consider John again, after first taking a moment to rewrite the beginning of his case study as follows:

John, 23, is the second son of separated parents. His father was a bare-knuckle boxer and an alcoholic who spent time in prison for violent offences, including against John's mother, who subsequently abandoned John and his brother with their father.

This rewritten childhood reveals early exposure to intra-marital and criminal violence, which may have retarded the development of his moral understanding; for example, his experiences might have inured his capacity for empathy and conceivably might also have led him to believe that using violence to resolve disputes can be morally acceptable. Now let us say that when he embezzled from his former employer he was fully aware of what he was doing. In Wolf's words:

'[h]e was neither coerced nor overcome by an irresistible impulse, and he was in complete possession of normal adult faculties of reason and observation. Yet it seems he ought not to be blamed for committing his crime, for, from his point of view, one cannot reasonably expect him to see anything wrong with his action. We may suppose that in his childhood he was given no love - he was beaten by his father, neglected by his mother. And that the people to whom he was exposed when he was growing up gave him examples only of evil and selfishness. From his point of view, it is natural to conclude that respecting other people's property would be foolish. For presumably no one had ever respected his. And it is natural for him to feel that he should treat other people as adversaries' (Wolf 1980: pp. 159-160).

This passage invites us to consider in a certain way the developmental process by which agents grow able to regard other people not as instruments of their own will but as autonomous agents. If a person is exposed to conditions that are hazardous to the maturation of empathy, then the assumption that this capacity will nonetheless develop (if in an impaired form) seems dubious. We have grown used to the point being made that many people who grow up in conditions of severe neglect and abuse nonetheless do not become psychopathic, but in the absence of an account of this resilience, the exemption theorist would presumably insist that this fact should strike us as astonishing. The puzzling question is not why someone who 
MCO answers

$\begin{array}{lllll}1 d & 2 b & 3 c & 4 b & 5 c\end{array}$ has grown up being disrespected should turn out to lack the capacity for empathy, but rather how anyone can develop the capacity at all under such hostile conditions.

One final point with regard to moral responsibility in psychopathy: the notion of conditions hazardous to the development of empathy should be read broadly, to refer not just to development but also to neurobiological conditions. This does not rule out the possibility that someone (like John in the original version of our vignette) who grows up in a caring home environment may nonetheless fail to mature empathically, owing to neurobiological impairments that inhibit speciestypical affective response. The key point here is that moral responsibility has epistemic conditions, one of which is the grasp of moral norms, and the causative factors that enable this understanding of moral norms to mature are contingent on the presence of fostering conditions, on both an autobiographical and an evolutionary timescale. Reflecting on the latter, Levy (2010) suggests a naturalistic account of the origin of moral norms, according to which their existence is dependent on our species being disposed to respond in various ways, for example, to the prospect of an innocent being harmed. But these responses on the part of moral agents emerge, in turn, through a process of evolution that selects for pro-social traits or dispositions. These dispositions are usually conceived of as affective capacities, and the severe impairment in these capacities that has been widely observed in psychopathic individuals signifies a failure to inherit the relevant dispositions, argues Levy. Thus, whether through faulty neurobiological mechanisms or through hostile conditions of upbringing (or a combination thereof), the development of empathy seems to be dependent on empirical fortune. The exemption theorist is moved by this seeming contingency of the development of empathy to conclude that the grasp of moral norms should by no means be assumed to be a universal achievement in the adult population of the human species.

These three considerations for exemption point toward the contingency of moral understanding and invite us to seriously entertain the possibility that the status of moral agent is one that not every adult human being achieves.

\section{Conclusions}

The range of exempting conditions recognised by criminal justice has expanded over centuries, owing principally to a greater appreciation of human interiority and the variation among human beings with regard to their internal landscapes.
B0X 4 Lessons to be learned

- Psychopathic individuals show characteristic deficits in empathy that may warrant a judgement that their moral responsibility is impaired or negated.

- The argument for impaired rather than negated moral responsibility (the mitigating view) relies on the apparent normalcy of a psychopathic individual - in the sense that they are not deluded or compelled. They also show evidence of a rule-based morality, although they may fail to distinguish moral rules from conventional ones.

- The argument for negated moral responsibility (the exempting view) builds on this failure, arguing that the gap between intellectual understanding and moral understanding may fatally undermine the ability of the psychopath to engage in moral reasoning.

- The application of philosophical reasoning can bring deeper understanding to complex issues in psychiatry.

From a legal situation in which no allowances were made even for children and the mentally ill, we now live in a world where the annihilating effects of florid psychosis on human moral agency are recognised and responded to appropriately (Mackay 1995). Whether psychopathy should be added to the list of exempting conditions remains to be seen.

In this debate, we have examined two opposing but related arguments. The nub of the disagreement is the extent to which psychopathy can be excusing. Advocates of the mitigating view argue that the psychopath's cognitive or factual understanding of actions others would see as morally bad is sufficient for a kernel of responsibility to be retained. Those who support the exempting view contend that it is not sufficient, instead arguing that their blindness to moral reasons means that psychopaths like John cannot be held morally responsible (the debate is summarised in Box 4).

What the foregoing discussion does make clear is that empirical work on the cognitive, affective and behavioural performance of psychopaths in laboratory conditions is not sufficient to settle the question. As it has always done, the work of assessing claims to moral exemption also requires us to inspect the contours of human interiority (to see whether it is possible to suffer from forms of blindness hitherto unrecognised) and to calibrate our conception of moral understanding and moral responsibility against what we find.

\section{References}

Blair J, Mitchell D, Blair K (2005) The Psychopath: Emotion and the Brain. Blackwell Publishing. 
Brown L (ed) (2009) The Nicomachean Ethics (trans WD Ross). Oxford University Press.

Cleckley H (1988) The Mask of Sanity (5th edn). Mosby.

Deigh J (1995) Empathy and universalizability. Ethics, 105: 743-63.

Duff, A (1977) Psychopathy and moral understanding. American Philosophical Quarterly, 14: 189.

Duff A (2010) Psychopathy and answerability. In Responsibility and Psychopathy (eds L Malatesti, J McMillan). Oxford University Press.

Glover J (2014) Alien Landscapes: Interpreting Disordered Minds. Harvard University Press.

Hare RD (1991) The Hare Psychopathy Checklist - Revised. Multi-Health Systems.
Levy N (2007) The responsibility of the psychopath revisited. Philosophy, Psychiatry \& Psychology, 14: 129-38.

Levy N (2010) Psychopathy, responsibility, and the moral/conventional distinction. In Responsibility and Psychopathy (eds L Malatesti, J McMillan). Oxford University Press.

Litton P (2008) Responsibility status of the psychopath: on moral reasoning and rational self-governance. Rutgers Law Journal, 39: 349-92.

Mackay RD (1995) Diminished responsibility and infanticide. In Mental Condition Defences in the Criminal Law. Clarendon Press.

Strawson PF (2003) Freedom and Resentment. In Free Will (2nd edn) (ed G Watson). Oxford University Press.

Wolf S (1980) Asymmetrical Freedom. Journal of Philosophy, 77: 151-66.

\section{MCOs}

Select the single best option for each question stem

1 The items in Hare's Psychopathy Checklist (Revised) do not include:

a impulsivity

b irresponsibility

c lack of empathy

d negative attitudes

e pathological lying.

2 The philosopher primarily associated with the idea of reactive attitudes is:

a Aristotle

b P. F. Strawson

c Immanuel Kant

d David Hume

e Galen Strawson.

\section{Moral responsibility:}

a is not related to voluntariness

b cannot be affected by mental illness

c can be defined as the extent to which an individual deserves a reward or punishment

$d$ cannot be defined by our reactive attitudes

$\mathrm{e}$ is always compatible with the doctrine of determinism.

4 The mitigating view of moral responsibility in psychopathy:

$a$ is not influenced by the apparent normalcy of the psychopathic individual

b is not incompatible with a failure to grasp the moral-conventional distinction

c would incline a court to deliver a verdict of not guilty by reason of insanity $d$ is favoured by philosophers

e asserts that the psychopath is blind to moral reasons.

5 Arguments to exempt a psychopath from moral responsibility:

a cannot be based on his developmental immaturity

b cannot be based on his failure to grasp the moral-conventional distinction

c can be based on failure to develop empathy due to neglect in childhood

d can be based on his evident lack of delusion or addiction

e are widely accepted. 